\title{
Financiamento das políticas sociais: o caso do Ministério da Saúde
}

Revista do

Serviço

Público

Ano 51

Número 3

Jul-Set 2000

\author{
Sérgio Francisco Piola \\ José Aparecido Carlos Ribeiro \\ Carlos Octávio Ocké Reis
}

\section{Introdução}

Conferir estabilidade ao financiamento público da saúde no campo das políticas sociais tem sido uma das principais preocupações dos gestores do Sistema Único de Saúde (SUS), bem como do Congresso Nacional.

Essa preocupação manifesta-se desde a elaboração do texto constitucional, com a aprovação do artigo 55 do Ato das Disposições Constitucionais Transitórias (ADCT). Esse artigo estabelecia que até que fosse aprovada a Lei de Diretrizes Orçamentárias (LDO), 30\%, no mínimo, do Orçamento da Seguridade Social (OSS), excluído o seguro-desemprego, seriam destinados ao setor saúde.

Ao atribuir transitoriedade a essa vinculação, o legislador constituinte estaria se posicionando contra uma vinculação específica e permanente, confiando que, a cada ano, a LDO estabeleceria um patamar adequado de recursos financeiros para a área de saúde.

Tal dispositivo, que tinha a limitação de referir-se apenas aos recursos federais, mostrou-se ineficaz em sucessivas LDOs. Desde então, trava-se um embate para definir na Constituição Federal (CF) um piso mínimo, permanente, de recursos financeiros públicos a serem aplicados no SUS. A crise de $1993^{1}$ — decorrente da retirada de recursos financeiros da saúde originários da Contribuição de Empregadores e Trabalhadores sobre a Folha de Salário - aguçou a problemática do financiamento setorial, além de provocar o surgimento de um conjunto de propostas de emenda constitucional na perspectiva de solucioná-la.

Em 1996, a criação da Contribuição Provisória sobre Movimentação Financeira (CPMF) foi uma solução transitória encontrada para suprir as

Sérgio

Francisco

Piola é médico-

sanitarista,

e representante

do Ministério

do Planejamento,

Orçamento

e Gestão no

Conselho Nacional de Saúde.

José Aparecido Carlos Ribeiro é economista, técnico de planejamento e pesquisa e professor de administração da AEUDF.

Carlos

Octávio Ocké

Reis é técnico de pesquisa e planejamento do IPEA.

Contatos: joserib@ipea.gov.br piola@ipea.gov.br octavio@ipea.gov.br 
necessidades do financiamento setorial. Até o ano de 1998, a CPMF destinava-se exclusivamente à saúde. No entanto, quando foi aprovada pela segunda vez, em 1999, a alíquota de contribuição passou de 0,20\% para $0,38 \%$, adicionando $0,18 \%$ para a previdência social e mantendo a alíquota de $0,20 \%$ para a saúde.

Nesse contexto, este trabalho pretende discutir o comportamento do financiamento federal da saúde no período 1993-1999, analisando as participações das diferentes fontes; a evolução dos gastos por categoria econômica de despesa e por subprogramas; além de avaliar os resultados da criação da CPMF. Igualmente, tenta demonstrar que, ao contrário do normalmente aceito, não foi a criação dessa contribuição que possibilitou o alcance de um novo patamar nas despesas federais com a saúde. Ao contrário, antes de sua criação, tais despesas já tinham tido uma primeira elevação. Finalmente, discutem-se as implicações da Proposta de Emenda Constitucional (PEC) 86A, recém-aprovada e promulgada pelo Senado como Emenda Constitucional (EC) $\mathrm{n}$ o 29, destacando seus aspectos mais importantes.

\section{Antecedentes históricos}

A Constituição de 1988 definiu que o SUS seria financiado fundamentalmente com recursos financeiros do OSS; da União, dos Estados, do Distrito Federal e dos municípios. Desse modo, as bases de sustentação financeira do OSS assenta-se nas seguintes fontes:

a) recursos dos orçamentos da União, dos Estados, do Distrito Federal e dos municípios;

b) recursos oriundos das contribuições sociais:

- dos empregadores, incidentes sobre a folha de salários, sobre o faturamento e, ainda, sobre o lucro líquido das empresas;

- dos trabalhadores;

- das receitas de concursos e prognósticos (loterias).

A única contribuição social que não fazia parte do financiamento dos gastos destinados ao setor saúde foi aquela relativa aos programas de proteção ao trabalhador. Tais programas são custeados com recursos financeiros vinculados ao Programa de Integração Social (PIS) / Programa de Formação do Patrimônio do Servidor Público (PASEP) por meio do Fundo de Amparo ao Trabalhador (FAT).

Vale dizer que não foi definida uma fonte específica para o setor saúde, nem tampouco foram definidos percentuais de vinculação no momento da arrecadação. Assim, em tese, a cada exercício fiscal, por intermédio da LDO, é definido o quanto de recursos financeiros do referido orçamento será destinado a cada uma dessas áreas: previdência social, saúde e assistência social. Contudo, no processo de execução orçamentária podem ocorrer flutuações no nível de recursos e na sua repartição entre as áreas. 
Contudo, quais foram os fatores que permitiram essas mudanças operadas no financiamento das políticas sociais, em particular, das políticas de saúde?

A experiência do Estado do bem-estar social europeu influenciou fortemente as forças políticas e sociais que defenderam a implementação do SUS no Brasil. Na Constituição de 1988, a atuação desse bloco histórico permitiu a criação de um "subsistema" de saúde que se pretende universal, eqüitativo e integral.

Nessa linha, esse novo modelo de proteção social acabou reestruturando o arcabouço institucional do aparelho estatal, sobretudo em relação à gestão e ao padrão de financiamento da política de saúde: antes da implantação do SUS, a medicina previdenciária era administrada pelo Ministério da Previdência Social e financiada principalmente por meio de contribuições previdenciárias.

Tais contribuições, que incidiam sobre a folha de salários e, portanto, estavam ligadas diretamente ao nível de emprego e à massa salarial, sofreram sérias restrições com a estagnação econômica da década de 80. As demais fontes de financiamento para saúde - tais como, o Fundo de Apoio ao Desenvolvimento Social (FAS), a Companhia de Financiamento Comercial (FINSOCIAL) e os recursos financeiros do próprio Tesouro Nacional tinham uma participação minoritária no total de gastos com a saúde.

Tornava-se então necessário criar fontes alternativas ao financiamento do setor saúde, sobretudo quando sabia-se que o Ministério da Previdência Social privilegiava o pagamento dos benefícios pecuniários em detrimento da assistência médica previdenciária. Além do mais, o setor saúde deveria contar com fontes de financiamento que estivessem desvinculadas do pagamento dos benefícios previdenciários, dado que a Constituição de 88 promoveu uma ampliação considerável dos direitos sociais no âmbito da previdência rural.

Para que o SUS - bem como para as áreas que compunham o OSS - estivesse apto a garantir bases materiais e efetivas para a concretização da universalização, era fundamental diversificar as fontes de financiamento. Por um lado, isso evitaria problemas derivados de oscilações macroeconômicas. Por outro, tendo em vista a redução estrutural do mercado formal de trabalho, tal diversificação tenderia a contrarrestar uma diminuição da base de financiamento, já que boa parte desse novo modelo baseava-se também na folha de salários. Desse modo, foi criada uma nova fonte, que incidia a partir de agora sobre o lucro líquido das empresas. Igualmente, foi elevada a alíquota da arrecadação do FINSOCIAL, que, a partir de 1989, veio a ser denominada Contribuição Social para o Financiamento da Seguridade Social (COFINS).

Porém, como o setor saúde pôde apresentar uma crise crônica de financiamento ao longo da década de 90 ? 
Tratando-se de um período relativamente longo, as interpretações que tentam explicar o estrangulamento do setor saúde, ou mesmo que procuram refutá-lo, são diversas. Para efeitos desse trabalho, cabe apenas lembrar que, na primeira metade dessa década, tal estrangulamento pode ter sido fruto, como já dissemos, do aumento dos gastos previdenciários em detrimento dos gastos na área da saúde. Ou ainda, simultaneamente, pode ter decorrido de um crescimento acentuado da demanda por bens e serviços públicos de saúde mais que proporcional ao crescimento das receitas no contexto da universalização do SUS. Finalmente, poder-se-ia atribuir a utilização de recursos financeiros do OSS para outros fins que não os da Seguridade Social, como no caso dos Encargos Previdenciários da União (EPUs) e da polêmica vinculação de receitas da Seguridade Social ao Fundo Social de Emergência (FSE) em 1994 (Ocké Reis, 1995).

A partir do Plano Real, como veremos a seguir, a constituição da CPMF teve exatamente como objetivo atenuar tal estrangulamento, sem necessariamente resolver a questão. Nessa perspectiva, a necessidade de se conferir estabilidade ao financiamento da saúde continua sendo um dos graves problemas no campo das políticas sociais. Seu encaminhamento vem se arrastando por quase oito anos, restando agora aguardar os resultados oriundos da implementação da emenda constitucional.

\section{O gasto total do Ministério da Saúde no período 1993-1999}

Observando a Tabela 1, nota-se que o gasto total do Ministério da Saúde ${ }^{2}$ apresentou um comportamento irregular ao longo do período 19931999. Cresceu 45\% entre 1993 e 1995, ao passar de um montante de $\mathrm{R} \$ 15,3$ bilhões para R $\$ 22,3$ bilhões. Apresentou posteriormente uma importante queda em 1996 (decréscimo de 19,2\% em relação ao ano de 1995), elevando-se novamente em 1997, quando atingiu o valor de R\$ 23,3 bilhões. Os gastos tornaram a cair nos anos de 1998 e 1999, situando-se entre R \$ 21 e 22 bilhões.

Em valores per capita, os dispêndios do Ministério da Saúde mantiveram-se entre R\$ 102 em 1993 e R\$132,9 em 1999. O valor máximo alcançado no período foi de R\$ 145,92 em 1997.

Do ponto de vista dos gastos do Ministério da Saúde como percentual do Produto Interno Bruto (PIB), a maior participação alcançada foi em $1995(2,31 \%)$. Nesse ano a estimativa do gasto público total em saúde, ou seja, a soma de todos os gastos da União, do Distrito Federal, dos Estados e dos municípios em relação ao PIB foi de 3,2\% (Vianna e Piola, 1998).

Na mesma linha, cotejando as experiências internacionais, segundo dados da Organização de Cooperação e Desenvolvimento Econômico (OCDE) para o mesmo ano, o gasto público total em saúde na França e 
na Espanha corresponderam, respectivamente, a 7,7\% e 5,8\% do PIB (Health Data Bank, 1996). Dados do Banco Mundial (World Development Indicators, World Bank CD-ROM, 1999) apontam também que os gastos públicos em saúde corresponderam a 4,3\%, 5,7\% e 7,9\% do PIB na Argentina, Inglaterra e Cuba respectivamente. Nos EUA, que têm um sistema de saúde assentado predominantemente no mercado, tais gastos alcançavam 6,6\% do PIB.

Tabela 1: Gasto total, per capita e proporção do PIB Ministério da Saúde

\begin{tabular}{l|c|c|c|c}
\hline Ano & $\begin{array}{l}\text { R\$ milhões } \\
\text { constantes } \\
\text { dez/99 }\end{array}$ & Índices & $\begin{array}{c}\text { Per capita } \\
\mathrm{R} \$ \text { de dez/99 }\end{array}$ & \% PIB \\
\hline 1993 & $15.385,4$ & 100,0 & 102,00 & $2,11 \%$ \\
1994 & $15.598,7$ & 101,4 & 102,02 & $2,15 \%$ \\
1995 & $22.298,9$ & 144,9 & 143,89 & $2,31 \%$ \\
1996 & $19.350,8$ & 125,8 & 123,19 & $1,85 \%$ \\
1997 & $23.233,1$ & 151,0 & 145,92 & $2,14 \%$ \\
$1998^{2}$ & $21.169,5$ & 137,6 & 131,18 & $1,94 \%$ \\
1999 & $21.791,1$ & 141,6 & 132,92 & n. disp. \\
\hline
\end{tabular}

Fonte: Siafi/Sidor. Elaboração: Ipea/Disoc.

${ }^{1}$ Valores deflacionados mês a mês pelo IGP/DI da FGV.

${ }^{2}$ Não incluído valor de R\$ 1.782 milhões correspondente à dívida do Ministério da Saúde, amortizada diretamente pela Secretaria do Tesouro Nacional.

Como veremos a seguir, para uma melhor análise dos dados apresentados na Tabela 1, devem ser feitas algumas ressalvas:

- a passagem para um nível mais elevado de dispêndio por parte do Ministério da Saúde ocorreu já em 1995, antes, portanto, da criação da CPMF;

- a execução financeira de 1998 ficaria muito mais próxima à de 1997, se nela fosse incluída o valor de R \$ 1,7 bilhão, correspondente à dívida do Ministério da Saúde amortizada diretamente pela Secretaria do Tesouro Nacional;

- o orçamento do Ministério da Saúde foi bastante pressionado pela amortização de dívidas contraídas principalmente junto ao $\mathrm{FAT}^{4} \mathrm{e}$ pelo pagamento dos EPUs, ou seja, as pensões e aposentadorias dos inativos. De forma que os recursos efetivamente disponíveis para o custeio das ações e serviços de saúde é, evidentemente, menor;

- o critério utilizado para a contabilização, ano a ano, das despesas é o de "empenho liquidado", que se aproxima do critério de fluxo de caixa. Nota-se, entretanto, que as flutuações anuais se apresentam mais discretas, quando adotado o "regime de competência" — já que os gastos são aí registrados no ano de origem da despesa (Quadro 1). 
A cada ano, uma parcela das despesas do governo federal tem o seu pagamento postergado para o exercício seguinte, constituindose nos "restos a pagar". Essas despesas, ao serem efetivamente liquidadas, são classificadas sob a rubrica "despesas de exercícios anteriores".

O quadro abaixo apresenta as despesas liquidadas, em cada ano, de forma discriminada: as despesas referentes a exercícios anteriores (coluna A) e as despesas referentes ao próprio exercício (coluna B). Em outras palavras, a coluna B apresenta os gastos "líquidos" do exercício, já retirados os gastos classificados como "despesas de exercícios anteriores" que constam na coluna A.

Somando essas duas colunas, temos o "regime de empenho liquidado" (coluna C), utilizado largamente nesse trabalho. Por outro lado, podemos construir uma proxy do "regime de competência" para um ano qualquer reintegrando as despesas deste ano que foram postergadas para o ano seguinte, ao mesmo tempo em que se excluem as despesas referentes a exercícios anteriores. Em outras palavras, ao somar a coluna B de um ano com a coluna A do ano seguinte, recuperam-se as "despesas de exercícios anteriores" de volta ao ano em que foram geradas, possibilitando uma aproximação dos totais sob a ótica do "regime de competência" (coluna D).

Pode-se perceber a partir daí que a execução orçamentáriofinanceira sob o regime de competência torna-se mais perene: por exemplo, a queda em 1996 se torna menos acentuada (ver Tabela 1).

\begin{tabular}{l|l|l|l|l}
\hline & $\begin{array}{l}\text { Despesas de } \\
\text { exercícios } \\
\text { anteriores(a) }\end{array}$ & $\begin{array}{l}\text { Despesas } \\
\text { líquidas do } \\
\text { exercício (b) }\end{array}$ & $\begin{array}{l}\text { Empenho } \\
\text { liquidado } \\
\text { (c) }\end{array}$ & $\begin{array}{l}\text { Regime de } \\
\text { competência } \\
\text { (d) }\end{array}$ \\
\hline 1993 & 1.624 .465 & 13.760 .898 & 15.385 .363 & 14.030 .155 \\
1994 & 269.257 & 15.329 .489 & 15.598 .746 & 16.582 .185 \\
1995 & 1.252 .697 & 21.046 .217 & 22.298 .914 & 22.338 .126 \\
1996 & 1.291 .909 & 18.058 .905 & 19.350 .814 & 20.991 .232 \\
1997 & 2.932 .326 & 20.300 .803 & 23.233 .130 & 20.797 .483 \\
1998 & 496.680 & 20.672 .826 & 21.169 .506 & 21.664 .125 \\
1999 & 991.298 & 20.799 .793 & 21.791 .091 & 20.799 .793 \\
\hline
\end{tabular}

Fonte: Siafi/Sidor. Elaboração: Ipea/Disoc.

Vale dizer que tal forma de calcular o gasto sob o "regime de competência", entretanto, é apenas uma aproximação, pois os dispêndios classificados sob a rubrica "despesas de exercícios anteriores" não se referem necessariamente ao exercício imediatamente anterior. 
Observando a Tabela 2, verificamos que a magnitude dos recursos financeiros disponíveis ao Ministério da Saúde para administrar e executar as ações e serviços de saúde — excluindo aqueles destinados à amortização de dívidas e ao pagamento de inativos - são menores: oscilaram entre $92 \%$ e $82 \%$ do total de gastos em 1993 e 1995 respectivamente. Desde o ano de 1995, os dispêndios financeiros com os EPUs mantiveram um patamar aproximado de $\mathrm{R} \$ 2$ bilhões. Os encargos da dívida, por sua vez, apresentaram uma tendência declinante nos dois últimos anos, pois seus serviços estão sendo quitados.

Em termos absolutos, esse quadro permite dizer que - embora os empréstimos em algum momento do tempo tenham sido convertidos em despesas correntes ou investimentos — em média, o Ministério da Saúde teve aproximadamente $\mathrm{R} \$ 2,5$ bilhões a menos para aplicar na área finalística. Considerando-se que as políticas de saúde produzem externalidades positivas ao bem-estar social da população, esse dado reflete a urgência de se garantir uma sólida base de financiamento à política setorial.

Tabela 2: Disponibilidade líquida para as ações e serviços de saúde Ministério da Saúde

\begin{tabular}{c|r|r|r|r|c}
\multicolumn{1}{c}{ Em R\$ milhões de dez/99 } \\
\hline Ano & Gasto total & EPU & \multicolumn{1}{c}{ Dívida } & Disp. líquida & $\begin{array}{c}\text { Disp. líquida \% } \\
\text { do gasto total }\end{array}$ \\
\hline 1993 & $15.385,4$ & $1.128,0$ & 71,7 & $14.185,70$ & $92,2 \%$ \\
1994 & $15.598,7$ & $1.111,2$ & 444,0 & $14.068,90$ & $90,0 \%$ \\
1995 & $22.298,9$ & $1.969,6$ & $2.008,8$ & $18.356,70$ & $82,2 \%$ \\
1996 & $19.350,8$ & $1.987,9$ & 668,0 & $16.726,50$ & $86,3 \%$ \\
1997 & $23.233,1$ & $1.943,7$ & $1.968,8$ & $19.358,30$ & $83,2 \%$ \\
1998 & $21.169,5$ & $2.109,4$ & 668,0 & $18.418,70$ & $86,9 \%$ \\
1999 & $21.791,1$ & $1.992,6$ & 168,6 & $19.629,90$ & $90,1 \%$ \\
\hline
\end{tabular}

Fonte: Siafi/Sidor. Elaboração: Ipea/Disoc.

O crescimento acelerado dos dispêndios com EPUs não é exclusividade do Ministério da Saúde. No quadro a seguir, vemos a evolução dos EPUs para alguns ministérios selecionados e para o conjunto do governo federal. Em diferentes níveis, tais gastos apresentaram um crescimento acentuado na esfera administrativa federal. ${ }^{5}$ 
Quadro 2: Evolução dos gastos com encargos previdenciários da União

\section{Ministérios selecionados}

Em R \$ milhões de dez/99.

Índice $1993=100$

\begin{tabular}{l|c|l|l|l|l|l|l|l|c}
\hline & 1993 & 1994 & 1995 & 1996 & 1997 & 94 & 95 & 96 & 97 \\
\hline $\begin{array}{l}\text { Min. da } \\
\text { Previdência }\end{array}$ & $1.580,2$ & $2.515,7$ & $2.847,6$ & $2.716,9$ & $2.750,0$ & 159,2 & 180,2 & 171,9 & 174,0 \\
\hline $\begin{array}{l}\text { Min. da } \\
\text { Educação }\end{array}$ & $1.496,5$ & $2.293,3$ & $2.234,5$ & $2.192,9$ & $2.226,4$ & 153,2 & 149,3 & 146,5 & 148,8 \\
\hline $\begin{array}{l}\text { Min. da } \\
\text { Saúde }\end{array}$ & $1.127,8$ & $1.160,6$ & $1.969,4$ & $1.987,7$ & $1.941,3$ & 102,9 & 174,6 & 176,3 & 172,1 \\
\hline $\begin{array}{l}\text { Min. do } \\
\text { Exército }\end{array}$ & $3.297,1$ & $3.154,9$ & $4.200,3$ & $4.316,0$ & $4.304,7$ & 95,7 & 127,4 & 130,9 & 130,6 \\
\hline $\begin{array}{l}\text { Min. da } \\
\text { Fazenda }\end{array}$ & $1.702,9$ & $1.667,6$ & $2.105,4$ & $1.999,9$ & $2.226,8$ & 97,9 & 123,6 & 117,4 & 130,8 \\
\hline $\begin{array}{l}\text { Total Gov. } \\
\text { Federal }\end{array}$ & $15.035,7$ & $19.820,2$ & $23.611,4$ & $23.424,8$ & $24.658,5$ & 131,8 & 157,0 & 155,8 & 164,0 \\
\hline
\end{tabular}

Fonte: Siafi/Sidor. Elaboração: Ipea/Disoc.

De outro ângulo, o Quadro 3 nos permite visualizar o conjunto da despesa federal. Apesar da constatação de um crescimento acentuado da magnitude da despesa financeira, o gasto do Ministério da Saúde não é desprezível, seja em relação à despesa não financeira $(10,8 \%$ e 9,7\%), seja em relação ao gasto social federal ${ }^{6}(17,8 \%$ e $15,5 \%)$, nos anos de 1994 e 1998 respectivamente.

Quadro 3: Gasto total do Ministério da Saúde comparação com as despesas do governo federal ${ }^{4}$

Em R \$ milhões correntes

\begin{tabular}{l|l|l}
\hline Especificação & 1994 & 1998 \\
\hline Desp. total do Gov. Federal(1) & 140.486 & 497.916 \\
\hline Despesa financeira(2) & 70.999 & 315.115 \\
\hline Desp. não financeira(3) & 69.487 & 182.801 \\
\hline Gasto social federal(5) & 42.174 & 113.905 \\
\hline Gasto do Min. da Saúde & 7.498 & 17.665 \\
\hline$\%$ MS/Desp. efetiva & 5,3 & 3,5 \\
\hline$\%$ MS/Desp. finan. & 10,6 & 5,6 \\
\hline \% MS/Desp.não finan. & 10,8 & 9,7 \\
\hline$\%$ Gasto social federal & 17,8 & 15,5 \\
\hline
\end{tabular}

Fonte: Siafi/Sidor. Balanços Gerais da União. Elaboração: Ipea/Disoc.

1) Despesa total, menos transferências intergovernamentais.

2) Despesas com juros e amortizações das dívidas interna e externa.

3) Despesa efetiva, menos despesa financeira.

4) Não houve possibilidade de incorporação dos dados do Balanço Geral da União de 1999.

5) Gasto mensurado segundo o conceito de Área de Atuação Social (metodologia DISOC/IPEA)? 


\section{Fontes dos recursos financeiros do Ministério da Saúde}

Ao contrário do que ocorre em países que adotam sistemas universais de atenção à saúde, aqui no Brasil, a participação de impostos gerais no financiamento do setor sempre foi residual.

Isso já ocorria antes da Constituição de 1988, quando mais de $80 \%$ do financiamento federal da saúde era proveniente da Contribuição de Empregadores e Empregados sobre a Folha de Salário. Após 1988, esse fenômeno volta a acontecer com o concurso das contribuições sociais vinculadas ao OSS. Será que esta tendência foi alterada na década de 90 ?

A partir das Tabelas 3 e 4 (e do Gráfico 1) se observa que as participações relativas das diferentes fontes no financiamento das despesas do Ministério da Saúde não apresentam um padrão estável. A cada ano, essas participações são bastante diferentes.

Enfatizamos a princípio que os Recursos Ordinários do Tesouro tiveram, ao longo do período analisado, uma participação pouco significativa no financiamento do Ministério da Saúde. Porém, tal participação apresenta-se fortemente crescente nos últimos anos: 10,8\% e 14,7\%, em 1998 e 1999 respectivamente. Nesse último ano, pode-se assinalar que a queda do ingresso de recursos financeiros oriundos da fonte CPMF, decorrente de sua não arrecadação durante alguns meses, foi compensada pelo aumento de recursos do Tesouro aplicados no Ministério da Saúde.

\section{Tabela 3: Distribuição do gasto,} segundo a fonte dos recursos

\section{Ministério da Saúde}

Em R \$ milhões de dez/99

\begin{tabular}{l|c|c|c|c|c|c|c}
\hline Fontes de Financiamento & 1993 & 1994 & 1995 & 1996 & 1997 & 1998 & 1999 \\
\hline Recursos Ordinários & $1.376,3$ & 156,1 & 703,2 & 38,3 & 237,3 & $2.285,3$ & $3.201,4$ \\
\hline $\begin{array}{l}\text { Títulos Resp. Tesouro } \\
\text { Nacional }\end{array}$ & $2.319,8$ & 251,9 & 587,3 & 648,2 & 648,2 & 98,3 & 165,9 \\
\hline $\begin{array}{l}\text { Operações Crédito } \\
\text { Internas - Moeda }\end{array}$ & 401,5 & - & $1.704,0$ & $1.598,1$ & - & - & - \\
\hline $\begin{array}{l}\text { Operações Crédito } \\
\text { Externas - Moeda }\end{array}$ & 71,2 & 187,3 & 237,6 & 165,4 & 115,9 & 223,6 & 315,7 \\
\hline $\begin{array}{l}\text { Recursos Diretamente } \\
\text { Arrecadados }\end{array}$ & 155,0 & 333,4 & 542,6 & 484,3 & 560,7 & 548,3 & 753,3 \\
\hline Contribuições Sociais & $10.377,3$ & $8.511,1$ & $15.465,6$ & $12.268,2$ & $16.984,9$ & $15.043,3$ & $13.621,3$ \\
\hline Contrib. Social Lucro PJ & $1.644,2$ & $2.013,7$ & $4.503,3$ & $4.022,2$ & $4.491,9$ & $1.690,3$ & $2.903,2$ \\
\hline COFINS & $3.868,5$ & $5.316,7$ & $10.962,3$ & $8.246,1$ & $6.025,7$ & $5.501,3$ & $5.797,9$ \\
\hline $\begin{array}{l}\text { Contrib. Emp. e Trab. } \\
\text { p/ Segurid. Social }\end{array}$ & $4.864,7$ & - & - & - & - & - & - \\
\hline CPMF & - & - & - & - & $6.467,3$ & $7.851,8$ & $4.920,1$ \\
\hline $\begin{array}{l}\text { FINSOCIAL - Recup. } \\
\text { Dep. Judiciais }\end{array}$ & - & $1.180,7$ & - & - & - & - & - \\
\hline Fundo de Estabilização Fiscal & - & $5.745,8$ & $2.665,2$ & $3.422,9$ & $4.530,9$ & $2.814,0$ & $3.085,3$ \\
\hline Demais Fontes & 684,2 & 413,2 & 393,3 & 725,4 & 155,3 & 156,7 & 648,2 \\
\hline Total & $15.385,4$ & $15.598,7$ & $22.298,9$ & $19.350,8$ & $23.233,1$ & $21.169,5$ & $21.791,1$ \\
\hline
\end{tabular}

Fonte: Siafi/Sidor. Elaboração: Ipea/Disoc. 
Tabela 4: Distribuição percentual

das fontes de financiamento

Ministério da Saúde

\begin{tabular}{l|r|r|r|r|r|r|c}
\hline $\begin{array}{l}\text { Fontes de } \\
\text { Financiamento }\end{array}$ & 1993 & 1994 & 1995 & 1996 & 1997 & 1998 & 1999 \\
\hline $\begin{array}{l}\text { Recursos } \\
\text { Ordinários }\end{array}$ & 8,9 & 1,0 & 3,2 & 0,2 & 1,0 & 10,8 & 14,7 \\
\hline $\begin{array}{l}\text { Títulos Resp. } \\
\text { Tesouro Nacional }\end{array}$ & 15,1 & 1,6 & 2,6 & 3,3 & 2,8 & 0,5 & 0,8 \\
\hline $\begin{array}{l}\text { Operações Crédito } \\
\text { Internas - Moeda }\end{array}$ & 2,6 & - & 7,6 & 8,3 & - & - & - \\
\hline $\begin{array}{l}\text { Operações Crédito } \\
\text { Externas - Moeda }\end{array}$ & 0,5 & 1,2 & 1,1 & 0,9 & 0,5 & 1,1 & 1,4 \\
\hline $\begin{array}{l}\text { Recursos Diretamente } \\
\text { Arrecadados }\end{array}$ & 1,0 & 2,1 & 2,4 & 2,5 & 2,4 & 2,6 & 3,5 \\
\hline Contribuições Sociais & 67,4 & 54,6 & 69,4 & 63,4 & 73,1 & 71,1 & 62,5 \\
\hline $\begin{array}{l}\text { Contrib. Social } \\
\text { Lucro PJ }\end{array}$ & 10,7 & 12,9 & 20,2 & 20,8 & 19,3 & 8,0 & 13,3 \\
\hline COFINS & 25,1 & 34,1 & 49,2 & 42,6 & 25,9 & 26,0 & 26,6 \\
\hline $\begin{array}{l}\text { Contrib. Emp. e Trab. } \\
\text { p/Segurid. Social }\end{array}$ & 31,6 & - & - & - & - & - & - \\
\hline CPMF & - & - & - & - & 27,8 & 37,1 & 22,6 \\
\hline $\begin{array}{l}\text { FINSOCIAL - Recup. } \\
\text { Dep. Judiciais }\end{array}$ & - & 7,6 & - & - & - & - & - \\
\hline $\begin{array}{l}\text { Fundo de Estabilização } \\
\text { Fiscal }\end{array}$ & - & 36,8 & 12,0 & 17,7 & 19,5 & 13,3 & 14,2 \\
\hline Demais Fontes & 4,4 & 2,6 & 1,8 & 3,7 & 0,7 & 0,7 & 3,0 \\
\hline Total & 100,0 & 100,0 & 100,0 & 100,0 & 100,0 & 100,0 & 100,0 \\
\hline Fone: SafiSin. Elaoc & & & & & & \\
\hline
\end{tabular}

Fonte: Siafi/Sidor. Elaboração: Ipea/Disoc.

Destacamos igualmente que as contribuições sociais no seu conjunto tiveram sua maior participação relativa em 1997 (73,0\%) e a menor em 1994 (54,5\%). Nota-se, que após o ano de 1997, houve uma nítida tendência de queda (sem alcançar, entretanto, os níveis do ano de 1994).

Avaliando a evolução dos dispêndios financeiros ano a ano, evidencia-se que em 1993, o Ministério da Saúde teve na contribuição sobre a folha de salários a sua principal fonte de financiamento. Essa fonte atendeu a 31,6\% de seus dispêndios. Foram também significativas as participações da COFINS $(25,1 \%)$ e dos Títulos sob a Responsabilidade do Tesouro Nacional $(15,1 \%)$.

O FSE criado em 1994, mais tarde rebatizado de Fundo de Estabilização Fiscal (FEF) ${ }^{8}$ teve já nesse ano uma participação considerável no financiamento do Ministério da Saúde, aproximadamente, $37 \%$ do total 
dos gastos. A COFINS, por sua vez, teve sua participação elevada para $34 \%$, como forma de contrabalançar a ausência de repasses da Previdência Social.

Em 1995 e 1996, a COFINS foi a principal fonte de financiamento do Ministério da Saúde. Nesses anos, a participação relativa dessa fonte na estrutura de despesas do Ministério da Saúde foi de 49,1\% e 42,5\%, respectivamente. Quase também duplicou a participação relativa dos recursos provenientes da Contribuição sobre o Lucro Líquido de Empresas (CSLL), que foi superior a 20\%. No entanto, a partir de 1998, essa fonte apresentou uma queda acentuada. ${ }^{9}$

\section{Gráfico 1: Evolução das fontes de financiamento do Ministério da Saúde}

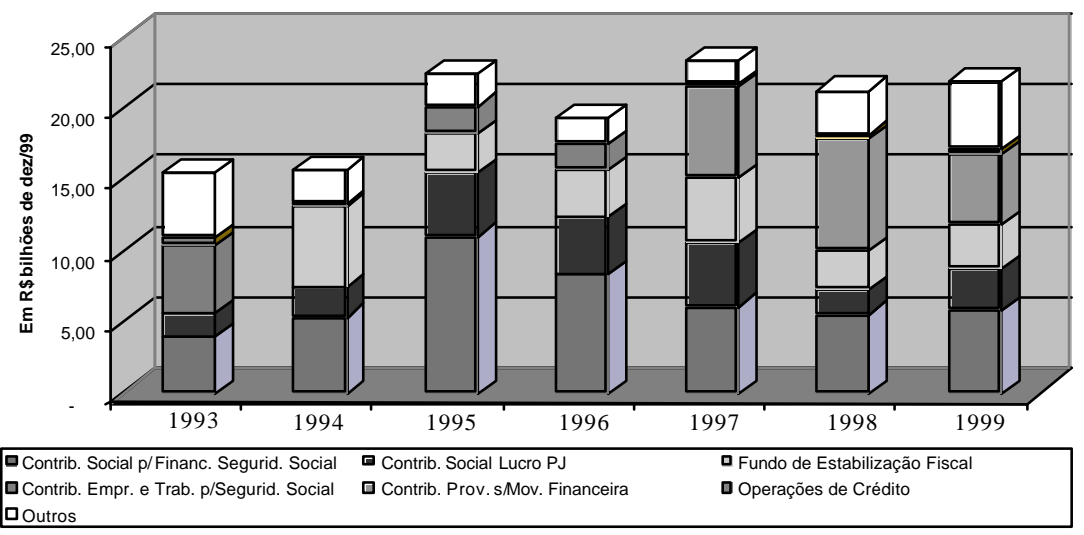

Em 1997 e 1998, a CPMF passou a ser a principal fonte de financiamento da saúde do governo federal. Em 1997 essa fonte foi responsável pelo custeio de quase $28 \%$ das despesas do Ministério da Saúde e em 1998 por $37 \%$. Durante esses dois anos, a contribuição da COFINS situouse em torno de $26 \%$, enquanto o FEF participou com $19,5 \%$ das despesas em 1997, 13,3\% em 1998 e 14,2\% em 1999.

O que poderia explicar essa verdadeira "dança" das fontes? A participação das fontes de financiamento é definida na LDO. No entanto, nem sempre a execução financeira, em termos de fontes, segue o que é definido na lei e, geralmente, não é feita a realocação final do montante a ser gasto pelas fontes.

Parece que há receio que a utilização sistemática de determinada fonte para determinado órgão crie uma expectativa de uma espécie de vinculação. Daí provavelmente essas contínuas alterações anuais, o que nos permite pensar na ausência de vontade política para garantir um 
volume adequado e regular de recursos para o financiamento das políticas públicas de saúde.

Contudo, a CPMF não veio exatamente para modificar esse quadro? Como mostra o Gráfico 2, a criação dessa nova contribuição acabou levando a uma retração de recursos de fontes que tradicionalmente financiavam o Ministério da Saúde. Apesar de ter sido alocada integralmente ao Ministério da Saúde, a CPMF não proporcionou uma elevação dos recursos, pelo menos na dimensão esperada, em decorrência da redução da participação de outras fontes.

A título de exemplo, se mantidos os montantes que as outras fontes aportavam em 1996 ( $\mathrm{R} \$ 19,35$ bilhões), ao acrescentarmos os recursos aplicados pela CPMF (Tabela 3), o Ministério da Saúde apresentaria um nível de dispêndio total de $\mathrm{R} \$ 25,8$ bilhões em 1997, $\mathrm{R} \$ 27,2$ bilhões em 1998 e $\mathrm{R} \$ 24,3$ bilhões em 1999, valores muito superiores aos efetivamente despendidos.

\section{Gráfico 2: Participação de CPMF e FEF nos gastos do Ministério da Saúde}

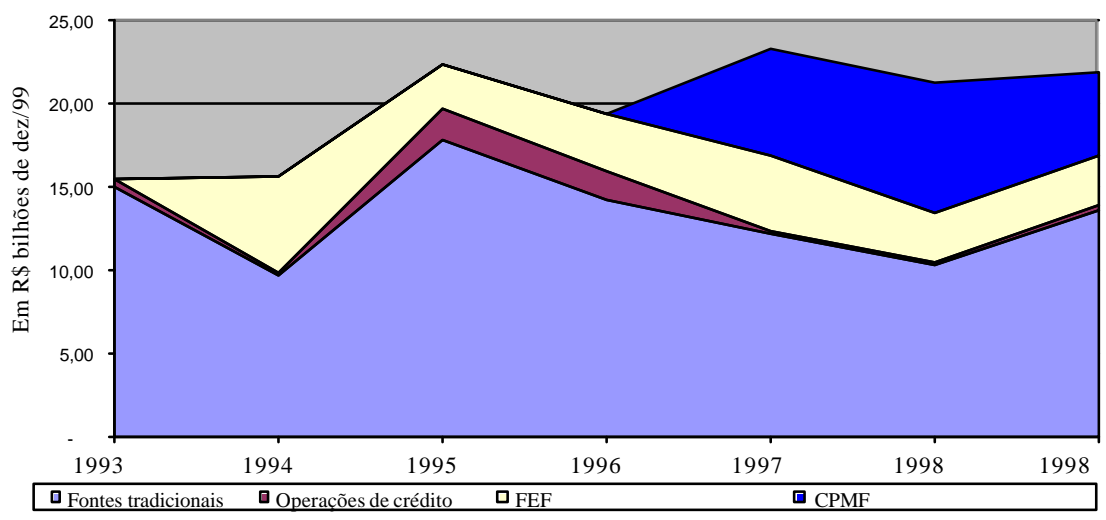

Fonte: Siafi/Sidor. Elaboração: Ipea/Disoc.

\section{Evolução do gasto segundo a categoria econômica da despesa}

A análise da evolução do gasto do Ministério da Saúde segundo a categoria econômica da despesa permite a verificação de algumas tendências importantes (Tabelas 5, 6 e Gráfico 3). 
Tabela 5: Gasto total segundo a categoria econômica Ministério da Saúde

\begin{tabular}{l|r|r|r|r|r|r|r}
\hline \multicolumn{1}{|c|}{ Natureza da Despesa } & 1993 & 1994 & 1995 & 1996 & 1997 & 1998 & 1999 \\
\hline Pessoal & $2.747,1$ & $3.401,9$ & $3.694,0$ & $3.203,8$ & $3.063,5$ & $2.719,7$ & $2.680,3$ \\
\hline $\begin{array}{l}\text { Outras Despesas } \\
\text { Correntes }\end{array}$ & $9.926,9$ & $9.327,6$ & $12.223,9$ & $10.745,8$ & $12.159,8$ & $8.973,2$ & $8.555,3$ \\
\hline Investimentos & 115,8 & 226,6 & 302,2 & 121,9 & 186,0 & 166,9 & 156,5 \\
\hline $\begin{array}{l}\text { Amort., Juros e } \\
\text { Encargos Dívida }\end{array}$ & 71,7 & 444,0 & $2.008,8$ & 668,0 & $1.968,8$ & 668,0 & 165,9 \\
\hline $\begin{array}{l}\text { Inativos e } \\
\text { Pensionistas }\end{array}$ & $1.127,8$ & $1.160,6$ & $1.969,4$ & $1.987,7$ & $1.941,3$ & $2.108,4$ & $1.993,2$ \\
\hline $\begin{array}{l}\text { Transf. Estados } \\
\text { e DF }\end{array}$ & 832,8 & 382,7 & 578,4 & 247,5 & 495,5 & 689,9 & 937,0 \\
\hline Transf. Municípios & 257,2 & 352,7 & $1.175,5$ & $2.058,6$ & $2.989,7$ & $5.090,4$ & $6.530,6$ \\
\hline Outros & 306,1 & 302,6 & 346,8 & 317,5 & 428,6 & 753,0 & 772,4 \\
\hline $\begin{array}{l}\text { Total } \\
21.791,1\end{array}$ & $15.385,4$ & $15.598,7$ & $22.298,9$ & $19.350,8$ & $23.233,1$ & $21.169,5$ & \\
\hline
\end{tabular}

Fonte: Siafi/Sidor. Elaboração: Ipea/Disoc.

O avanço do processo de descentralização do SUS é inegável. $\mathrm{O}$ percentual de recursos financeiros descentralizados para Estados e municípios subiu de 7,1\% em 1993 para 34,3\% em 1999. Esse percentual se tornaria ainda mais significativo, caso retirássemos as despesas "não descentralizáveis" como pessoal (inativos e pensionistas) e como o pagamento da dívida (amortização e os encargos financeiros). Nesse caso, cerca de 38,0\% dos recursos disponibilizados ao Ministério da Saúde em 1999 seriam descentralizados. 
Tabela 6: Distribuição percentual do gasto total por categoria econômica Ministério da Saúde

\begin{tabular}{l|c|c|c|c|c|c|c}
\hline Natureza da Despesa & 1993 & 1994 & 1995 & 1996 & 1997 & 1998 & 1999 \\
\hline Pessoal & 17,9 & 21,8 & 16,6 & 16,6 & 13,2 & 12,8 & 12,3 \\
\hline $\begin{array}{l}\text { Outras Despesas } \\
\text { Correntes }\end{array}$ & 64,5 & 59,8 & 54,8 & 55,5 & 52,3 & 42,4 & 39,3 \\
\hline Investimentos & 0,8 & 1,5 & 1,4 & 0,6 & 0,8 & 0,8 & 0,7 \\
\hline $\begin{array}{l}\text { Amort. Juros } \\
\text { e Encargos Dívida }\end{array}$ & 0,5 & 2,8 & 9,0 & 3,5 & 8,5 & 3,2 & 0,8 \\
\hline $\begin{array}{l}\text { Inativos e } \\
\text { Pensionistas }\end{array}$ & 7,3 & 7,4 & 8,8 & 10,3 & 8,4 & 10,0 & 9,1 \\
\hline $\begin{array}{l}\text { Transf. Estados } \\
\text { e DF }\end{array}$ & 5,4 & 2,5 & 2,6 & 1,3 & 2,1 & 3,3 & 4,3 \\
\hline $\begin{array}{l}\text { Transf. } \\
\text { Municípios }\end{array}$ & 1,7 & 2,3 & 5,3 & 10,6 & 12,9 & 24,0 & 30,0 \\
\hline Outros & 2,0 & 1,9 & 1,6 & 1,6 & 1,8 & 3,6 & 3,5 \\
\hline Total & 100 & 100 & 100 & 100 & 100 & 100 & 100 \\
\hline Fonte: Sif/Sin
\end{tabular}

Fonte: Siafi/Sidor. Elaboração: Ipea/Disoc.

Em termos absolutos, o montante de recursos descentralizados para os municípios aumentaram de $\mathrm{R} \$ 255$ milhões em 1993 para $\mathrm{R} \$$ 6,5 bilhões em 1999.

\section{Gráfico 3: Gastos por natureza de despesa Ministério da Saúde}

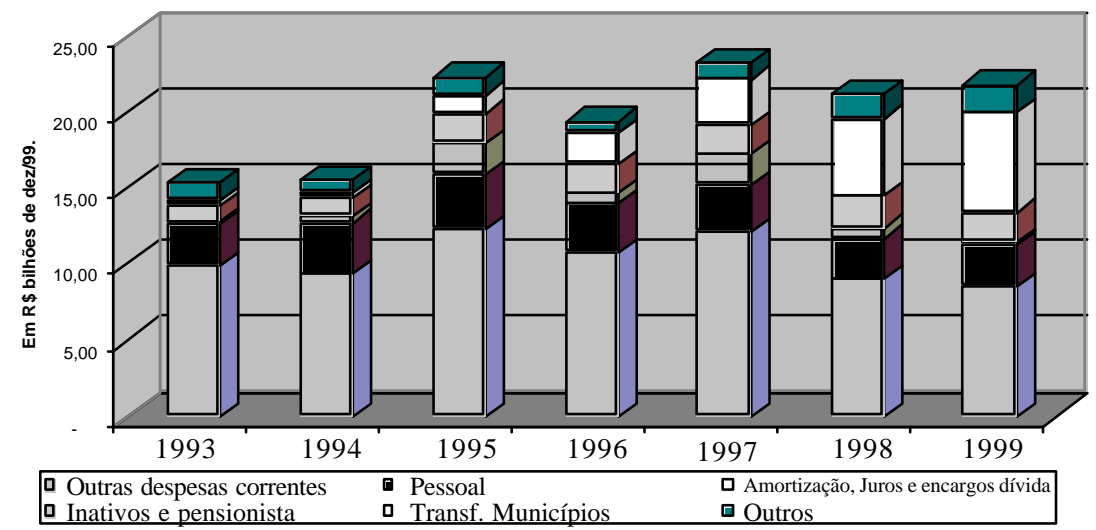

Fonte: Siafi/Sidor. Elaboração: Ipea/Disoc. 
Apesar da importância da Norma Operacional Básica (NOB) do SUS 01/93 (NOB 01/93) ${ }^{10}$ para a avanço do processo de descentralização, foi indubitavelmente a aprovação da NOB 01/96 que intensificou tal processo, sobretudo por meio dos repasses do Piso da Atenção Básica $(\mathrm{PAB}) .{ }^{11}$ Esse Piso possibilitou que um grande número de municípios se habilitassem à condição de gestores da atenção básica. Também cresceu o número de municípios que se habilitaram à gestão plena de seus sistemas municipais. ${ }^{12}$ Esses dois movimentos constituem a principal explicação para o significativo incremento dos repasses do Ministério da Saúde para a esfera municipal, que saltam de $\mathrm{R} \$ 2,1$ bilhões em 1996 para 6,5 bilhões em 1999.

O repasse dos recursos financeiros para a gestão estadual teve comportamento mais estável e modesto. Em 1999, por exemplo, alcançou a cifra de R $\$ 937$ milhões. Isso pode ser explicado, por um lado, pela tendência municipalista observada no processo de descentralização na saúde e, por outro, pelo fato de que os Estados estavam mais reticentes na assunção das responsabilidades inerentes à gestão descentralizada. ${ }^{13}$

Os gastos com pessoal ativo, que cresceram até o ano de 1995, passam a apresentar, desde então, uma tendência declinante, reflexo da política governamental de contenção dos gastos com pessoal e da aposentadoria de parcelas significativas do quadro de pessoal. Em contrapartida, os gastos com inativos e pensionistas alcançam um novo patamar a partir de 1995, quando atingem a magnitude de $\mathrm{R} \$ 1,9$ bilhão. A partir daí, o gasto se manteve nesse nível ao longo do período.

As despesas com investimentos diretos do Ministério da Saúde são pouco significativas, apenas em dois anos, 1994 e 1995, ficam em torno de 1,4\% do dispêndio total da instituição. Por sua vez, as despesas com amortização e encargos da dívida têm uma participação elevada: os valores despendidos em 1995 e 1997 chegaram a $R$ \$ 2 bilhões e representaram cerca de $9 \%$ do gasto total do ministério. ${ }^{14}$

\section{Dispêndios por subprogramas}

A maior parte dos dispêndios do Ministério da Saúde tem sido realizada por meio do subprograma Assistência Médica e Sanitária, que inclui os recursos financeiros destinados ao custeio da assistência ambulatorial e hospitalar. Da forma em que são usualmente apresentados, os dados não permitem visualizar alterações significativas operadas na política assistencial em direção ao atendimento ambulatorial, como o Programa dos Agentes Comunitários de Saúde (PACS) e o Programa de Saúde da Família (PSF), por exemplo. 
Tabela 7: Gasto total por subprograma Ministério da Saúde

Em R \$ milhões de dez/99

\begin{tabular}{l|r|r|r|r|r|r|r}
\hline Subprogramas & 1993 & 1994 & 1995 & 1996 & 1997 & 1998 & 1999 \\
\hline $\begin{array}{l}\text { Assistência Médica } \\
\text { e Sanitária }\end{array}$ & $11.086,3$ & $9.259,7$ & $12.463,4$ & $11.965,1$ & $13.820,9$ & $13.289,0$ & $13.848,1$ \\
\hline $\begin{array}{l}\text { Contr. Doenças } \\
\text { Transmissíveis }\end{array}$ & 650,8 & 359,2 & 398,3 & 192,6 & 591,9 & 530,9 & 683,9 \\
\hline Vigilância Sanitária & 10,1 & 2,8 & 5,6 & 6,3 & 25,0 & 59,5 & 139,9 \\
\hline $\begin{array}{l}\text { Profiláticos e } \\
\text { Terapêuticos }\end{array}$ & 645,8 & 465,5 & 791,1 & 457,8 & 880,6 & 859,3 & $1.268,2$ \\
\hline EPU & $1.128,0$ & $1.109,4$ & $1.966,4$ & $1.984,7$ & $1.940,6$ & $2.106,7$ & $1.992,6$ \\
\hline Dívida & 71,7 & 443,2 & $2.005,5$ & 666,9 & $1.965,6$ & 667,1 & 168,6 \\
\hline Saneamento & 49,2 & 83,8 & 88,5 & 77,1 & 195,7 & 304,1 & 366,9 \\
\hline $\begin{array}{l}\text { Alimentação } \\
\text { e Nutrição }\end{array}$ & 43,6 & 68,6 & 191,4 & 46,3 & 127,6 & 73,4 & 154,3 \\
\hline Administração & $1.277,9$ & $3.426,8$ & $3.975,2$ & $3.579,1$ & $3.349,8$ & $2.982,9$ & $2.909,5$ \\
\hline Outros & 421,9 & 379,7 & 413,4 & 374,9 & 335,5 & 296,7 & 259,2 \\
\hline Total & $15.385,4$ & $15.598,7$ & $22.298,9$ & $19.350,8$ & $23.233,1$ & $21.169,5$ & $21.791,1$ \\
\hline
\end{tabular}

Fonte: Siafi/Sidor. Elaboração: Ipea/Disoc.

Verifica-se, entretanto, que o abono de $25 \%$ concedido em junho de 1996 à tabela de preços dos procedimentos ambulatoriais e hospitalares não impactou na mesma proporção sobre a magnitude do subprograma Assistência Médica Sanitária. A política racionalizadora implementada pelo Ministério da Saúde, que estabeleceu tetos físicos e financeiros, acabou obrigando os Estados e municípios a reduzirem sua produção ambulatorial e hospitalar.

É importante também notar que nos anos em que a disponibilidade financeira foi menor, como ocorreu em 1996, um dos subprogramas mais atingidos foi o de Controle de Doenças Transmissíveis, responsável pelo financiamento das campanhas de vacinação, controle de endemias etc., e de outras ações de vigilância epidemiológica. Em outras palavras, pelo financiamento da produção de bens tipicamente públicos no setor saúde. Vale dizer, esse subprograma apresentou uma redução significativa de gastos em 1996, apesar de apresentar uma recuperação sensível em 1997 e 1998 (Tabelas 7 e 8). 
Tabela 8: Distribuição percentual do

gasto total por subprograma

Ministério da Saúde

\begin{tabular}{l|r|r|r|r|r|r|c}
\hline Subprogramas & 1993 & 1994 & 1995 & 1996 & 1997 & 1998 & 1999 \\
\hline $\begin{array}{l}\text { Assistência Médica } \\
\text { e Sanitária }\end{array}$ & 72,06 & 59,36 & 55,89 & 61,83 & 59,49 & 62,77 & 63,55 \\
\hline $\begin{array}{l}\text { Controle Doenças } \\
\text { Transmissíveis }\end{array}$ & 4,23 & 2,30 & 1,79 & 1,00 & 2,55 & 2,51 & 3,14 \\
\hline Vigilância Sanitária & 0,07 & 0,02 & 0,03 & 0,03 & 0,11 & 0,28 & 0,64 \\
\hline $\begin{array}{l}\text { Profiláticos e } \\
\text { Terapêuticos }\end{array}$ & 4,20 & 2,98 & 3,55 & 2,37 & 3,79 & 4,06 & 5,82 \\
\hline EPU & 7,33 & 7,11 & 8,82 & 10,26 & 8,35 & 9,95 & 9,14 \\
\hline Dívida & 0,47 & 2,84 & 8,99 & 3,45 & 8,46 & 3,15 & 0,77 \\
\hline Saneamento & 0,32 & 0,54 & 0,40 & 0,40 & 0,84 & 1,44 & 1,68 \\
\hline Alimentação e & 0,28 & 0,44 & 0,86 & 0,24 & 0,55 & 0,35 & 0,71 \\
Nutrição & & & & & & & \\
\hline Administração & 8,31 & 21,97 & 17,83 & 18,50 & 14,42 & 14,09 & 13,35 \\
\hline Outros & 2,74 & 2,43 & 1,85 & 1,94 & 1,44 & 1,40 & 1,19 \\
\hline Total & 100 & 100 & 100 & 100 & 100 & 100 & 100 \\
\hline
\end{tabular}

Fonte: Siafi/Sidor. Elaboração: Ipea/Disoc.

\section{Perspectivas do financiamento da saúde}

Como se observou anteriormente, a discussão sobre a vinculação de recursos para o custeio do SUS é antiga. A primeira proposta já constava do ADCT, quando da promulgação da Constituição de 1988.

$\mathrm{Na}$ década de 90 foram apresentadas um conjunto de $\mathrm{PEC}$, que propunha a vinculação de recursos ao setor saúde. A primeira - que emergiu como resposta ao afastamento dos recursos previdenciários do financiamento da saúde - foi a PEC 169-A, de autoria dos deputados Eduardo Jorge (PT/SP) e Waldir Pires (PDT/BA). Por intermédio dessa PEC, o artigo 198 da CF, passaria a ter a seguinte redação: “A União aplicará anualmente, na implementação do SUS, nunca menos de trinta por cento $(30 \%)$ das receitas de contribuições sociais que compõem o OSS e dez por cento (10\%) da receita de impostos" e "Os Estados, o Distrito Federal e os municípios aplicarão anualmente, na implementação do SUS, nunca menos de $10 \%$ das receitas resultantes de impostos".

Essa proposta vinculava recursos financeiros no âmbito da Seguridade Social para a saúde, da mesma forma que garantia a aplicação de um patamar mínimo de recursos por parte dos Estados, Distrito Federal e municípios. O relator da proposta, deputado Darcísio Perondi (PMDB/RS), 
alterou a vinculação para $30 \%$ do OSS, não a restringindo mais às receitas das contribuições sociais exclusivamente. Por outro lado, excluiu da proposta a obrigatoriedade da União aplicar $10 \%$ da receita de impostos na área de saúde.

Além da PEC 169-A, merecem destaque as propostas apresentadas pelos deputados José Aristodemo Pinotti (PMDB/SP) e pelo deputado Carlos Mosconi (PSDB/MG). A primeira propunha que o setor público de saúde fosse financiado com recursos equivalentes a 5\% do PIB do ano anterior. A segunda (PEC 82-A), determinava a vinculação dos recursos financeiros da COFINS e da CSLL para a saúde. ${ }^{15}$

Em 1998, a Comissão Especial que avaliou a PEC 82-A, tendo como relator o deputado Ursicino Queiroz (PFL/BA), elaborou um substitutivo que compatibilizou aspectos das propostas dos deputados Carlos Mosconi, Eduardo Jorge e outros. Após intensas negociações, foi aprovada pela Câmara, em votação de dois turnos, a PEC no 82-C. Essa proposta tramitou no Senado como PEC 86-A e acabou sendo aprovada e promulgada como EC no 29.

Os principais pontos do dispositivo aprovado são os seguintes:

a) acrescenta, nos artigos 34 e 35 da $\mathrm{CF}$, nova hipótese de intervenção da União nos Estados, Distrito Federal e municípios e do Estado em seus municípios, no caso de não ser cumprida a aplicação do mínimo previsto de suas receitas em ações e serviços públicos de saúde;

b) acrescenta dispositivo ao parágrafo primeiro do art. 156 da $\mathrm{CF}$ permitindo aos municípios estabelecer progressividade na cobrança do Imposto Predial e Territorial Urbano (IPTU) em função do valor do imóvel e ter alíquotas diferenciadas de acordo com a localização e uso do imóvel;

c) condiciona, no art. $160 \mathrm{da} \mathrm{CF}$, a entrega dos recursos transferidos pela União e pelos Estados ao atendimento da vinculação definida pela emenda;

d) permite, no art. 167 da $\mathrm{CF}$, a vinculação de receita de impostos às ações e serviços de saúde ${ }^{16}$

e) determina, como regra permanente, no art. 198 da $\mathrm{CF}$, que a União, os Estados, o Distrito Federal e os municípios aplicarão, anualmente, em ações e serviços públicos de saúde, recursos mínimos. No caso dos Estados, Distrito Federal e dos municípios, ${ }^{17}$ os percentuais serão calculados sobre a arrecadação de impostos e as transferências constitucionais. No caso da União, na forma em que for definida nos termos de Lei Complementar;

f) prevê a promulgação de Lei Complementar onde essas medidas serão reavaliadas pelo menos a cada cinco anos, tanto para estabelecer os percentuais mínimos de aplicação quanto para definir critérios de rateio dos recursos transferidos pela União aos Estados, ao Distrito Federal e aos municípios e pelos Estados aos seus municípios. A Lei Complementar 
também deverá estabelecer: 1) Os critérios de rateio para a distribuição dos recursos, objetivando a progressiva redução das disparidades regionais. 2) As normas de fiscalização, avaliação e controle das despesas com saúde nas esferas federal, estadual e municipal. 3) As normas de cálculo do montante a ser aplicado pela União;

g) insere novo artigo (art. 77) no ADCT, de forma a estabelecer todas as regras para a aplicação dos dispositivos da emenda, enquanto não entrar em vigor a Lei Complementar que definirá os percentuais de vinculação;

h) define ( $\S 1^{\circ}$ doart. 77) que, no caso da União, no ano 2000, o total de recursos mínimos aplicado em ações e serviços de saúde será equivalente ao montante empenhado no exercício financeiro de 1999 acrescido de, no mínimo, 5\%. Do ano 2001 ao ano 2004, o valor mínimo será aquele apurado no ano anterior, corrigido pela variação nominal do PIB. No caso dos Estados e do Distrito Federal, os recursos mínimos serão equivalentes a $12 \%$ da arrecadação de impostos e das transferências constitucionais, deduzidas as parcelas que forem transferidas aos municípios. No caso dos municípios, os recursos mínimos deverão ser equivalentes a $15 \%$ da arrecadação de impostos e dos recursos de transferências constitucionais;

i) estabelece, para o caso dos Estados, Distrito Federal e municípios que aplicam menos do que os percentuais previstos, a obrigação de elevarem, progressivamente, suas aplicações até 2004, na razão de pelo menos um quinto por ano;

j) define que a partir de 2000, as aplicações dos Estados, Distrito Federal e municípios serão de pelo menos $7 \%$;

k) cria regra que obriga a aplicação nos municípios em ações e serviços básicos de saúde de no mínimo $15 \%$ dos recursos federais vinculados ao setor. A Lei Complementar disporá sobre o assunto, incluindo o rateio desses recursos segundo o critério populacional;

1) determina que os recursos das três esferas de governo sejam aplicados por meio dos Fundos de Saúde - que serão acompanhados e fiscalizados pelos Conselhos de Saúde;

m) mantém as regras do art. 77 (ADCT), a partir de 2005, caso não seja criada a Lei Complementar referida no $\S 3^{\circ}$ do art. 198.

A EC no 29, ao contrário de propostas anteriores, não buscou, no âmbito dos recursos da União, a vinculação de fontes ou de um percentual do OSS à área da saúde. Estabelece, para o governo federal, a obrigatoriedade da aplicação de um patamar mínimo de recursos, variável no tempo, com base na variação nominal do PIB. Essa mudança, em relação às propostas anteriores, foi determinada pela perspectiva de aprovação de projeto de reforma tributária que extingue a maior parte das contribuições sociais que hoje integram o OSS e mantém apenas a vinculação da contribuição sobre a folha de salários para a previdência social. ${ }^{18}$ 
Um dos problemas iniciais da $\mathrm{EC}$ no 29 é que ela não define - o que necessariamente deve ser feito na Lei Complementar - o que se entende por ações e serviços públicos de saúde. A questão parece ser trivial, mas não é. Por exemplo, no caso da União, qual será o critério para se estabelecer o montante de recursos empenhados em 1999 e que servirá de base para o cálculo do valor para os anos seguintes? Será o valor da despesa federal com saúde que, nesse caso, incluiria os gastos de outros órgãos federais, como as aplicações do Ministério da Educação nos Hospitais Universitários e de Ensino e os gastos do Governo Federal na manutenção dos serviços de saúde do Distrito Federal? Serão considerados, exclusivamente, os dispêndios realizados por intermédio do Ministério da Saúde? ${ }^{19}$

O mesmo problema surge na definição e no acompanhamento das despesas que devem ser feitas pelos Estados, Distrito Federal e municípios. Serão consideradas as despesas feitas na manutenção dos serviços de saúde das previdências estaduais e municipais e nos serviços de saúde das Polícias Militares? Ou somente serão considerados os serviços de clientela universalizada? E os gastos com saneamento básico? Ademais, serão computados os gastos com inativos e pensionistas da área da saúde? A PEC poderia ter evitado essa polêmica, caso houvesse definido que a vinculação era para o custeio dos serviços do SUS.

Um ponto que traz dificuldade para a aplicação imediata da EC é a carência de informações mais confiáveis sobre os gastos dos Estados e municípios com recursos próprios. Com o objetivo de trazer informações mais regulares e confiáveis sobre esta questão, o Ministério da Saúde vem desenvolvendo o Sistema Integrado de Orçamento Público da Saúde (SIOPS), que já está apresentando bons resultados.

Outro ponto, refere-se à data de vigência da EC, que é o ano 2000. Nesse ano, os Estados, o Distrito Federal e os municípios deveriam estar aplicando em saúde no mínimo 7\% de suas receitas de impostos, deduzidas as parcelas transferidas. Porém, como atender a esta obrigação já no final do exercício? As alternativas seriam: 1) Considerar o primeiro ano de vigência da EC como sendo 2001. 2) Considerar que os Estados e municípios com aplicações abaixo de $7 \%$ de suas receitas na data da promulgação da Emenda deveriam, na confecção do orçamento para 2001, prever não só o alcance do patamar de 7\%, mas ainda acrescentar a parcela correspondente à redução de um quinto da diferença até $12 \% \mathrm{e}$ $15 \%$, respectivamente.

A promulgação da EC veio tornar mais patente a necessidade de aprimoramentos no sistema de levantamento das despesas setoriais. Como se sabe, apenas as despesas realizadas com recursos do governo federal recebem um acompanhamento mais sistemático. A mais recente consolidação do gasto público total em saúde, refere-se ao ano de 1995, e foi 
elaborada pela Diretoria de Estudos Sociais do IPEA em 1998. ${ }^{20}$ Nesse estudo, o gasto público total em saúde foi estimado em $\mathrm{R} \$ 21,7$ bilhões, sendo que $63,0 \%$ dos recursos são originários de fontes administradas pelo governo federal. Só mais recentemente, como dito anteriormente, montou-se o SIOPS, que pode ser uma fonte de informação mais regular sobre os gastos públicos com saúde.

A EC no 29 ainda tem outros pontos obscuros. Ela determina, ${ }^{21}$ por exemplo, que a alocação dos recursos da União para Estados, Distrito Federal e municípios, e dos Estados destinados aos municípios, obedecerá a critérios de rateio que objetivem a progressiva redução das disparidades regionais. Porém, que tipo de disparidade se quer corrigir? Na distribuição dos recursos públicos, na utilização de serviços ou nas condições de saúde? Logicamente, a depender do resultado que se queira corrigir, os parâmetros a serem utilizados serão diferentes.

\section{Considerações finais}

São crescentes as dificuldades que se interpõem à consolidação de um sistema público de saúde de acesso universal e com um bom padrão de qualidade. Apesar de um aumento da carga tributária global de $27 \%$ para $31 \%$ nos últimos anos, conferir estabilidade ao financiamento da saúde no campo das políticas sociais constitui-se em um dos maiores desafios do Estado brasileiro.

A partir de 1996, pôde-se mesmo evidenciar que a introdução da CPMF atenuou a redução de recursos financeiros alocados ao Ministério da Saúde que estava se delineando. No entanto, cabe ressaltar, que essa injeção de recursos financeiros adicionais por meio da CPMF, não representou um novo patamar de gastos, pois do ano de 1997 em diante a CPMF acabou cumprindo o papel de substituir as fontes de recursos que vinham financiando o setor. Por outro lado, as despesas com as dívidas e os EPUs desviaram recursos da ordem de R \$ 2,5 bilhões das atividades finalísticas da área de saúde por ano no período 1993-1999.

Os debates sobre o volume e a regularidade dos recursos financeiros destinados ao SUS sempre privilegiaram a discussão dos recursos financeiros originados da União. A EC no 29 deverá permitir que o financiamento local do SUS ganhe a relevância que precisa ter no desenho das políticas e dar maior estabilidade ao processo de estabilização.

Resta saber se o pesado programa de ajuste financeiro do governo federal sobre as contas públicas dos Estados e municípios dificultará o aporte de recursos das esferas subnacionais, atualmente, tão necessários. Comparando com outros países, os gastos públicos em saúde no Brasil como proporção do PIB são parcos, em que pese que o gasto do Ministério da Saúde não seja desprezível em relação ao gasto total do governo federal. 
Por fim, cabe ressaltar que apesar da referida instabilidade financeira do setor saúde, diversos avanços foram realizados, principalmente após a aprovação da NOB 01/96. Esses avanços se configuram na criação no $\mathrm{PAB}$, no aumento no número de municípios habilitados à gestão plena de seus sistemas, na definição de critérios para descentralização da gestão de recursos para o desenvolvimento de vários programas e ações entre os quais se destaca o PSF. Ou seja, pode-se dizer que engendra-se um novo modelo assistencial mais adequado ao formato organizacional do SUS.

\section{| Notas}

${ }^{1}$ No bojo do OSS, entre os anos de 1990 e 1993, as despesas com os benefícios previdenciários apresentaram um crescimento de $47 \%$, enquanto que, no mesmo período, as transferências totais (Tesouro e Instituto Nacional do Seguro Social) para o Ministério da Saúde tiveram um crescimento inferior a 3\%. Além do mais, tais gastos previdenciários cresceram de 61,5\% em 1991 para 65,3\% em 1992. Dessa forma, esse aumento dos gastos previdenciários provocou uma drástica redução da transferência de recursos, permitindo o aparecimento de uma grave crise financeira do SUS. Ver BARros, M. E., Piola, S. F., Vianna, S.M. (1996), Política de Saúde no Brasil: Diagnóstico e Perspectivas, TD n. 401, IPEA.

2 Além de todas as unidades orçamentárias do órgão 36000 (Ministério da Saúde), estão computados aqui os valores da unidade orçamentária 72136 (Encargos Previdenciários da União-Recursos sob Supervisão do Ministério da Saúde). Até o exercício de 1995, existiam, para cada órgão, unidades orçamentárias destinadas aos lançamentos contábeis dos encargos previdenciários da União. Para garantir a compatibilidade entre os anos da série, essa unidade orçamentária foi integrada às demais unidades do Ministério da Saúde.

3 Os dados do Banco Mundial não indicam exatamente o ano correspondente ao dado. Diz apenas que tratam-se "de dados do ano mais recente disponível", dentro de uma série histórica que vai de 1990 a 1997.

${ }^{4}$ Em 1993, 1995 e 1996 o Ministério da Saúde tomou empréstimos junto ao FAT para o pagamento da assistência médico-hospitalar.

5 Uma das explicações mais aceitas para justificar a trajetória ascendente dos EPUs surge da constatação de uma reação defensiva dos servidores públicos frente à incerteza das consequiências da Reforma da Previdência.

6 Apurado segundo a metodologia DISOC/IPEA. Para maiores detalhes, ver Fernandes et al (1998b) e Fernandes (2000).

7 Conforme Fernandes (2000:16), “... o conceito de área de atuação orienta o agrupamento das despesas de caráter social segundo o critério de objetivo ou finalidade dos gastos, na tentativa de promover uma melhor aproximação possível da ação efetiva dos dispêndios junto à população beneficiária. A forma de agregação utilizada não é, portanto, compatível com os registros das despesas por órgão setorial (critério institucional), nem com os levantamentos das despesas por funções ou programas (enfoque funcional), formatos usuais de apresentação das contas do setor público." 
8 Por intermédio do FEF, o governo federal teve como objetivo aumentar o volume de recursos desvinculados no orçamento federal. Além do mais, tentou dessa forma diminuir os repasses obrigatórios da União para Estados e municípios por meio do Fundo de Participação Estadual (FPE) e Fundo de Participação Municipal (FPM). No âmbito do OSS, pretendeu igualmente contornar a obrigatoriedade prevista na lei no 8.212/91 (Lei de Financiamento e Custeio da Seguridade Social), que previa percentuais decrescentes de utilização de recursos de contribuições sociais para o pagamento de EPUs.

9 Em 1995 e 1996, a participação relativa dos recursos financeiros do FEF decresceu. De outra parte, foi significativa a participação de recursos oriundos de Operações de Crédito Internas para custear os gastos do Ministério da Saúde: 7,6\% em 1995 e 8,2\% em 1996.

${ }^{10}$ Até janeiro de 1997, 3.127 municípios, representando 62,9\% do total, haviam se habilitado a alguma das formas de gestão estabelecidas pela NOB 01/93. Desses 3.127 municípios, 2.367 foram habilitados à gestão incipiente $(75,7 \%), 616$ (19,7\%) à gestão parcial e 144 (4,6\%) à gestão semiplena (MS/SAS/SPS 1999).

${ }^{11}$ Com o PAB passaram a ser repassados mensalmente recursos financeiros equivalentes a 1/12 do montante de $\mathrm{R} \$ 10,00$ por habitante/ano para o custeio da atenção básica (a parte fixa do PAB).

12 Apesar de publicada em novembro de 1996, a NOB 01/96 foi implementada somente a partir de janeiro de 1998. De janeiro de 1998 a abril de 1999, 5.222 municípios (quase 95\% do total) estavam habilitados em alguma das duas novas formas de gestão descentralizada: 4.752 (86,3\% do total) estavam habilitados como gestores da PAB e 470 ( $8,5 \%$ do total) habilitados como gestores plenos do sistema municipal de saúde (idem 1999).

13 Até abril de 1999, apenas poucos Estados estavam habilitados nas novas condições de gestão estabelecidas pela NOB 01/96. Alagoas habilitou-se na gestão plena do sistema e o Distrito Federal, Minas Gerais, São Paulo, Rio Grande do Sul e Bahia na condição de gestão avançada do sistema estadual. O Rio Grande do Sul estava solicitando a mudança da gestão avançada para plena e o Paraná, Santa Catarina e Pará, solicitando a habilitação na gestão plena (ibdem 1999).

${ }^{14}$ Com a progressiva quitação da dívida, houve naturalmente uma redução do patamar desses gastos — que alcançam $\mathrm{R} \$ 668$ milhões em 1998.

${ }^{15}$ Para maiores detalhes sobre as diferentes PECs, inclusive sobre as estimativas de receitas, consultar Marques (1999); Jaegger e Carvalho (1998).

${ }^{16}$ O texto constitucional permitia, até a promulgação da EC no 29 , apenas a vinculação para a área de educação no caso da manutenção do desenvolvimento do ensino.

${ }^{17}$ No caso dos Estados e do Distrito Federal, a vinculação incide sobre o produto da arrecadação dos impostos a que se refere o art. 155 e dos recursos que tratam dos incisos I (a) e II dos artigos 157 e 159, da CF, deduzidas as parcelas que forem transferidas aos respectivos municípios. No caso dos municípios e do Distrito Federal,incide sobre o produto da arrecadação de impostos a que se refere o art. 156 e dos recursos de que trata o inciso I (b) do § 3o dos artigos 158 e 159 da CF.

${ }^{18}$ A proposta aprovada na Comissão Especial da Câmara dos Deputados vem recebendo severas críticas do Ministério da Fazenda, do Presidente do Senado e de setores empresariais, supondo-se que dificilmente será aprovada em sua atual formulação e até mesmo que a reforma será postergada.

${ }^{19} \mathrm{Na}$ ausência dessas definições têm sido feitos diversos contatos, ainda que informais, entre o Executivo, Conselho Nacional de Saúde e o Legislativo. Nas negociações iniciais, a base proposta para o âmbito federal é a despesa realizada pelo Ministério da Saúde, excluídos os gastos com inativos e pensionistas e com amortização da dívida.

${ }^{20}$ Fernandes et al (1998b).

${ }^{21}$ Inciso II do § 3o do art. 198. 


\section{Referências bibliográficas}

Barros, M.E., Piola, S.F., Vianna, S.M. (1996), Política de Saúde no Brasil: Diagnóstico e Perspectivas, TD 401, IPEA.

Brasil. Câmara dos Deputados. (1999), Proposta de Emenda à Constituição no 82-C de 1995. Brasília.

Fernandes, M.A. (2000), Mensuração do Gasto Público Social: a metodologia desenvolvida na Diretoria de Estudos Sociais do IPEA (mimeo). Brasília: IPEA.

Fernandes, M.A. et al.(1998 a), Dimensionamento do Gasto Social Federal. TD 547. Brasília:IPEA.

.(1998 b), Gasto Social das Três Esferas de Governo, 1995. TD 598. Brasília:IPEA.

JaegGer, M.L., CARvalho, G. A.(1998), "A questão do financiamento suficiente e definitivo para a saúde: as PECs e o ano de 1998". Conselho Nacional de Saúde, Mimeo.

M Arques, R.M.(1999), "O financiamento do sistema público de saúde brasileiro", Série Financiamento del Desarollo, no 82, CEPAL.

MS/SAS/SPS.(1999), "Análise de Alguns Aspectos do Processo de Descentralização do Sistema Único de Saúde".

Ocké Reis, C.O.(1995), O Setor Privado de Saúde. Limites da Autonomia. Tese de Mestrado apresentada no Instituto de Medicina Social da UERJ,p. 203.

Ocké Reis, C.O., De Aquino, L.M., Nogueira, R.P.(1999), "Financiamento Público dos Recursos Humanos em Saúde: o Caso do Nordeste". Série Estudos em Saúde Coletiva, no 194, Instituto de Medicina Social da UERJ.

Vianna, S.M., Piola, S.F. (1998), "Descentralização e Gestão do Gasto Público". Compendio de Documentos: Taller sobre Evaluación de la Géstión del Gasto Público en Salud (CEPAL/BID/IPEA), p.105-140. 
Conferir estabilidade ao financiamento público da saúde no campo das políticas sociais tem sido uma das principais preocupações de amplos setores da sociedade e do Estado. Este artigo visa contribuir com essa discussão a partir de um contexto específico: avaliar o comportamento das fontes de recursos e dos gastos do Ministério da Saúde.

Serão analisadas: a) a composição do financiamento por fontes; b) a evolução dos gastos por categoria econômica da despesa e por subprogramas; e c) a evolução da CPMF.

Em especial, discutiremos qual o impacto deste novo "tributo" (CPMF) sobre o financiamento do Ministério da Saúde. Finalmente, apresentamos uma visão prospectiva sobre a EC no 29, que define novas regras para o financiamento das políticas de saúde no país.

\section{Financiamiento de las políticas sociales: el caso del Ministerio de la Salud} Sérgio Francisco Piola, José Aparecido Carlos Ribeiro y Carlos Octávio Ocké Reis

Una de las principales preocupaciones de amplios sectores de la sociedad y del Estado está relacionada con la estabilidad de las fuentes de financiamiento público de la salud. Este artículo pretende contribuir con esa discusión a partir de un contexto específico: evaluar el comportamiento de las fuentes de recursos y de los gastos del Ministerio de la Salud.

Serán analizadas: a) la composición del financiamiento por fuentes; b) la evolución de los gastos por categoria econômica de erogaciones y por sub-programas; y c) la evolución de la CPMF.

En especial, discutiremos cual es el impacto de este nuevo "tributo" (CPMF) sobre el financiamiento del Ministerio de la Salud. Finalmente, presentamos una visión prospectiva sobre la EC no 29, que define las nuevas reglas para el financiamiento de las políticas de salud en el país.

\section{Financing of the social policies: the case of the Ministry of Health \\ Sérgio Francisco Piola, José Aparecido Carlos Ribeiro and Carlos Octávio Ocké Reis}

The stabilization of public health financing has been one of the main concerns of various areas of society and of the State. This article contributes to this discussion from a specific context: to evaluate the behavior of the resource funds and expenses of the Ministry of Health.

The composition of finance by sources; the evolution of expenses by economic category and sub programs; and the evolution of CPMF will all be analyzed. We also discuss the impact of this new "tribute" (CPMF) about the financing of the Ministry of Health.

Finally, we present a prospective vision of the $29^{\text {th }}$ Amendment which defines new rules to the financing of health policies in the country.

Sérgio

Francisco

Piola é médicosanitarista, e representante do Ministério do Planejamento, Orçamento e Gestão no Conselho Nacional de Saúde.

José Aparecido Carlos Ribeiro é economista, técnico de planejamento e pesquisa e professor de administração da AEUDF.

Carlos Octávio Ocké Reis é técnico de pesquisa e planejamento do IPEA. 